\title{
Characterization of peripartum rumination and activity of cows diagnosed with metabolic and uterine diseases
}

\author{
Daniela N. Liboreiro, ${ }^{\dagger} \dagger$ Karine S. Machado, ${ }^{*}$ Paula R. B. Silva, $†$ Milton M. Maturana, ${ }^{*}$ Thiago K. Nishimura, ${ }^{\star}$ \\ Alice P. Brandão, ${ }^{*}$ Márcia I. Endres, $†$ and Ricardo C. Chebel ${ }^{*} \dagger \ddagger \S^{1}$ \\ *Department of Veterinary Population Medicine, and \\ †Department of Animal Science, University of Minnesota, St. Paul 55108 \\ ‡Department of Large Animal Clinical Sciences, and \\ §Department of Animal Sciences, University of Florida, Gainesville 32608
}

\begin{abstract}
The objectives of the current experiment were to characterize the correlation among total serum $\mathrm{Ca}$, nonesterified fatty acids (NEFA), $\beta$-hydroxybutyrate (BHBA), and haptoglobin concentrations and daily rumination time (DRT) and activity of periparturient cows and to determine the association between periparturient events and peripartum DRT and activity. Holstein animals (nulliparous $=77$, parous $=219$ ) were enrolled in the experiment approximately $21 \mathrm{~d}$ before expected calving date. Cows were fitted with individual Heat Rumination Long Distance collars (HRLD, SCR Engineers Ltd., Netanya, Israel) from enrollment until approximately $21 \pm 3 \mathrm{~d}$ postpartum. Blood samples collected weekly from enrollment to $21 \mathrm{~d}$ postpartum were used to determine concentrations of NEFA, BHBA, and haptoglobin. Blood samples collected within $72 \mathrm{~h}$ after calving were used to determine total serum Ca concentration. Subclinical ketosis was characterized by BHBA $>1,000 \mu \mathrm{mol} / \mathrm{L}$ in any sample, and subclinical hypocalcemia was characterized by $\mathrm{Ca}<8.55 \mathrm{ng} / \mathrm{dL}$ within $72 \mathrm{~h}$ after calving. Cows were examined 1, $7 \pm 3$, and $14 \pm 3 \mathrm{~d}$ postpartum for diagnosis of retained fetal membrane and metritis. Total Ca $(\mathrm{r}=0.15)$, NEFA ( $\mathrm{r}$ $=-0.27)$, and haptoglobin $(\mathrm{r}=-0.18)$ concentrations were weakly correlated with DRT. Concentration of BHBA $(\mathrm{r}=-0.14)$ was weakly correlated with activity. Postpartum DRT was reduced among cows that delivered twins compared with cows that delivered singletons $(437.9 \pm 4.8$ vs. $385.9 \pm 17.1 \mathrm{~min} / \mathrm{d})$. Prepartum (465.8 \pm 4.1 vs $430.8 \pm 14.9$ arbitrary units) and postpartum $(536.5 \pm 5.5$ vs. $480.3 \pm 19.4$ arbitrary units) activity were reduced among cows that delivered twins compared with cows that delivered singletons.
\end{abstract}

Received October 7, 2014.

Accepted June 8, 2015.

${ }^{1}$ Corresponding author: rcchebel@ufl.edu
Delivery of stillborn calves was associated with reduced DRT prepartum $(478.0 \pm 5.9$ vs. $417.0 \pm 23.4 \mathrm{~min} / \mathrm{d})$ and postpartum $(437.2 \pm 4.8$ vs. $386.5 \pm 19.3 \mathrm{~min} / \mathrm{d})$. On the other hand, cows delivering stillborn calves had increased activity prepartum compared with cows delivering live calves $(499.3 \pm 16.2$ vs. $461.3 \pm 4.1$ arbitrary unit). Occurrence of retained fetal membrane tended to and was associated with reduced prepartum (444.3 \pm 11.0 vs. $466.5 \pm 4.3$ arbitrary unit) and postpartum (488.2 \pm 14.5 vs. $538.8 \pm 5.7$ arbitrary unit) activity, respectively. Cows diagnosed with metritis had reduced postpartum DRT $(415.9 \pm 10.1$ vs. $441.0 \pm 5.2 \mathrm{~min} / \mathrm{d})$ and activity $(512.5 \pm 11.5$ vs. $539.2 \pm 6.0$ arbitrary unit). Postpartum activity was reduced among cows that were diagnosed with subclinical ketosis (502.20 \pm 16.5 vs. $536.6 \pm 6.2$ arbitrary unit). Although differences in DRT and activity between populations of cows that developed periparturient diseases and healthy cows were observed, further experiments are necessary to determine how DRT and activity data may be used to precociously diagnose individuals that will develop such periparturient diseases.

Key words: periparturient cow, rumination, activity

\section{INTRODUCTION}

The peripartum period is very challenging to the dairy cow because of hormonal, metabolic, and managerial changes. The amount and daily variability in DMI during the transition period is probably the most important factor affecting the health and performance of dairy cows (Grummer et al., 2004). Previous research has shown that cows that develop metritis postpartum have reduced prepartum feed intake, which is likely a predisposing factor for immunosuppression and greater susceptibility to uterine infections (Hammon et al., 2006; Huzzey et al., 2007). Dry matter intake and feeding and lying behaviors are also associated with metabolic diseases and lameness. Cows that developed subclinical hypocalcemia within $24 \mathrm{~h}$ after calving tended to have 
fewer daily visits to the water trough and feed bins but few changes in standing time and DMI were observed (Jawor et al., 2012). When hypocalcemia was induced in nonpregnant nonlactating cows, DMI was reduced by approximately $45 \%$ within the period of induced hypocalcemia (Martinez et al., 2014). Goldhawk et al. (2009), using a BHBA threshold $>1,000 \mu \mathrm{mol} / \mathrm{L}$ for diagnosis of subclinical ketosis (SCK), demonstrated that cows diagnosed with SCK had reduced DMI, reduced number of daily visits to the feeder, and reduced time spent at the feeder. Edwards and Tozer (2004) demonstrated that the pattern of activity, measured by pedometry (Kibbutz Afikim, Israel), of cows that were diagnosed with displacement of abomasum and ketosis was different from the activity pattern of healthy cows. Therefore, it seems clear that the ability to monitor peripartum DMI, feeding behavior, and activity of individual cows and groups of cows could aid in the early identification of unhealthy cows and management deficiencies that predispose to such diseases.

Automated technologies for monitoring behavior of dairy cows have recently become more widely adopted in the United States. Recent experiments have demonstrated that the Heat Rumination Long Distance collars (HRLD, SCR Engineers Ltd., Netanya, Israel) is accurate in measuring rumination of different types of cows (prepartum and postpartum) compared with visual observation (Schirmann et al., 2009). Although the HRLD system was not able to correctly predict individual cows' DMI within a day and was actually negatively correlated with DMI within 2-h periods and with daily feeding time (Schirmann et al., 2012), changes in rumination over time are expected to reflect changes in DMI. Furthermore, these monitors could be used as tools for early diagnosis of periparturient events (e.g., calving) and peripartum health disorders. Schirmann et al. (2013) demonstrated that daily rumination time (DRT) decreased by approximately 63 and 133 min during the $24 \mathrm{~h}$ before and $24 \mathrm{~h}$ after calving, respectively. Similarly, feeding time was decreased by approximately 66 and $82 \mathrm{~min}$ during the $24 \mathrm{~h}$ before and $24 \mathrm{~h}$ after calving, respectively (Schirmann et al., 2013).

The hypotheses of the current experiment were that peripartum DRT and activity are correlated with concentrations of metabolites (e.g., Ca, NEFA, and BHBA) and haptoglobin. Furthermore, we hypothesized that periparturient metabolic and infectious disorders are associated with DRT and activity. The objectives of the current experiment were to determine the correlation among concentrations of metabolites and haptoglobin and DRT and activity of periparturient cows and to characterize the periparturient DRT and activity pat- terns of cows diagnosed with metabolic and uterine disorders.

\section{MATERIALS AND METHODS}

\section{Cows, Facilities, Management, and Nutrition}

The experiment was conducted on one dairy farm in northwestern Wisconsin from July 2013 to April 2014, with Holstein animals enrolled from July 2013 to October 2013 and calving occurring from August 2013 to November 2013. Holstein animals (nulliparous $=77$, parous $=219$ ) were enrolled in the experiment at $258.3 \pm 0.2 \mathrm{~d}$ of gestation (mean \pm SEM). During the prepartum period, animals were separated by parity (nulliparous vs. parous) and housed in 1 of 3 freestall pens with 3 rows of stalls. The barns were naturally ventilated and had artificial lighting. The stocking density ranged from 85 to $110 \%$ of headlocks in the pen of nulliparous animals and from 60 to $90 \%$ in the pens of parous animals. As animals demonstrated signs of calving (discomfort, restlessness, tail twitching, and visualization of the allantoic sac through the vulva), they were moved to a loose housing pen with straw bedding.

During the immediate postpartum period (1 to 21 \pm 3 DIM), primiparous and multiparous animals were commingled in 1 freestall pen with 3 rows of stalls. The barns were naturally ventilated and had artificial lighting. From 1 to $21 \pm 3$ DIM, pens were stocked at 80 and $95 \%$ of headlocks and stalls, respectively. From $21 \pm 3$ DIM until the end of lactation, cows were housed in a cross-ventilated freestall barn with stocking density varying between 110 and $120 \%$ of headlocks and between 119 and $130 \%$ of stalls.

From enrollment to calving, nulliparous and parous animals were fed the same TMR except that the TMR of parous animals contained anionic salts. From 1 DIM to the end of lactation, primiparous and multiparous cows were fed the same TMR. During the prepartum period, the TMR was offered once a day; during the postpartum period, the TMR was offered once a day during the winter and twice a day during the summer ( $70 \%$ in the a.m. and $30 \%$ in the p.m.).

\section{Rumination and Activity}

Cows were fitted with HRLD collars (SCR Engineers Ltd.) from -21 to $21 \pm 3$ d relative to calving. Rumination was recorded in minutes per 2 -h intervals, and total rumination minutes per day was used for statistical analysis unless otherwise stated. Activity was recorded every $2 \mathrm{~h}$ and total activity per day was used for statistical analysis unless otherwise stated. 


\section{BCS and Locomotion Score}

At enrollment, $3 \pm 3$, and $24 \pm 3$ DIM, all cows were scored for body condition $(1=$ emaciated and 5 $=$ obese; 0.25 -unit increments as described by Ferguson et al., 1994) and locomotion $(1=$ normal locomotion and $5=$ severely lame; as described by Sprecher et al., 1997). Cows with locomotion score $\geq 3$ were considered lame.

\section{Blood Sampling and Analysis of Metabolites, Haptoglobin, and Total Calcium}

Blood samples were collected from all cows $-18 \pm 3$, $-11 \pm 3,-4 \pm 3,3 \pm 3,10 \pm 3$, and $17 \pm 3$ d relative to calving from the coccygeal vein/artery immediately after feeding while cows were restrained in self-locking headlocks. Needles used were 22 -gauge and 1 inch long, and samples were collected into empty evacuated tubes and evacuated tubes containing $\mathrm{K}_{2}$ EDTA (Becton Dickinson Vacutainer Systems, Franklin Lakes, NJ). Tubes were placed in ice until centrifugation for plasma separation $\left(1,200 \times g\right.$ for $15 \mathrm{~min}$ at $\left.4^{\circ} \mathrm{C}\right)$. Plasma was aliquoted into microcentrifuge tubes and stored at $-32^{\circ} \mathrm{C}$ until analysis.

Samples collected weekly from $-17 \pm 3$ to $17 \pm 3$ $\mathrm{d}$ relative to calving were analyzed for concentrations of NEFA using a colorimetric assay (Wako Chemicals USA, Richmond, VA; Ballou et al., 2009). Concentrations of BHBA were determined enzymatically (Ranbut, Randox Laboratories, Antrim, UK; Ballou et al., 2009) in samples collected weekly from $1 \pm 1$ to 17 \pm 3 DIM. A plate reader (Spectramax 340; Molecular Devices, Sunnyvale, CA) was used to measure the absorbance for the colorimetric and enzymatic assays. Control serum (Randox Control Sera, Antrim, UK) was used for the NEFA and BHBA assays. The intraassay CV were 6.1 and $9.8 \%$ for the NEFA and BHBA assays, respectively. The interassay $\mathrm{CV}$ were 8.9 and $11.8 \%$ for the NEFA and BHBA assays, respectively.

Haptoglobin concentration was determined in samples collected $-17 \pm 3,-11 \pm 3,-4 \pm 3,3 \pm 3,10 \pm 3$, and $17 \pm 3 \mathrm{~d}$ relative to calving. A colorimetric procedure using a plate reader (Spectramax 340; Molecular Devices, Sunnyvale, CA) to measure absorbance was used to determine haptoglobin concentration (Hulbert et al., 2011). The intraassay and interassay CV were 4.1 and $9.8 \%$, respectively.

Total serum Ca concentration was determined using a colorimetric assay described by Goff et al. (2012) and Oetzel (1996). The interassay and intraassay CV were 2 and $5 \%$, respectively.

\section{Clinical Examination and Definitions of Diseases}

All cows were examined at $1,7 \pm 3$, and $14 \pm 3$ DIM for diagnosis of retained fetal membrane (RFM) and metritis. Retained fetal membrane was defined as retention of fetal membrane past $24 \mathrm{~h}$ postpartum. Metritis was defined as cows having watery, pink/brown, and fetid uterine discharge (LeBlanc, 2010). Cows that had at least one blood sample with BHBA concentration $>1,000 \mu \mathrm{mol} / \mathrm{L}$ were considered to have SCK. Cows with $\mathrm{Ca}$ concentrations $<8.55 \mathrm{ng} / \mathrm{dL}$ in blood samples collected within $72 \mathrm{~h}$ after calving were considered to have subclinical hypocalcemia.

\section{Milk Production}

Cows were milked thrice daily and individual milk yield and milk conductivity data were recorded at each milking (AfiMilk, Kibbutz Afikim, Israel). Milk yield and conductivity data were collected daily in the first 21 DIM and weekly thereafter. For purposes of statistical analysis, daily milk yield from calving to 17 DIM and average milk yield in the first 90 DIM (90dMilk) were used.

\section{Environment Data}

Temperature and humidity data were collected using Hobo loggers (Onset Computer Corp., Pocasset, MA) installed in each of the barns in which prepartum and postpartum cows were housed. Temperature-humidity index (THI) was calculated for every 2-h interval within a 24-h period (12 intervals) and daily for each barn. The percentage of 2 -h intervals with THI $>68$ was calculated for each day.

\section{Statistical Analysis}

This was an observational cohort experiment. Animals were enrolled in weekly cohorts of 5 to 50 animals. The correlation among daily milk yield (first 17 DIM) and concentrations of metabolites (NEFA and BHBA), total serum $\mathrm{Ca}$, and haptoglobin and rumination and activity were evaluated using MedCalc Software (Ostend, Belgium). Partial correlations that included days relative to calving, parity, week of calving, BCS at enrollment, calf sex, and number of calves (singleton vs. twins) as explanatory variables were used to evaluate the correlation among daily milk yield (first 17 DIM) and concentrations of metabolites (NEFA and BHBA), total serum $\mathrm{Ca}$, and haptoglobin and rumination and activity. Furthermore, average milk yield in the first 90 DIM was compared with prepartum and postpartum average DRT and activity. 
Continuous data were analyzed by ANOVA for repeated measurements using the MIXED procedure of SAS (version 9.2; SAS/STAT, SAS Inst. Inc., Cary, NC). The structure of covariance (auto-regressive, unstructured, or compound symmetry) was chosen according to the Bayesian and Akaike information criteria. Prepartum and postpartum behavior (DRT and activity) were analyzed separately because of the distinct patterns of DRT and activity during the prepartum and postpartum periods. Calving day ( $\mathrm{d} 0$ ) was included in the postpartum period. Univariate analyses were used to determine the association between animal characteristics (calf sex and twin birth) and behavior (DRT, activity) and between health events (stillbirth, subclinical hypocalcemia, RFM, metritis, and SCK) and behavior (DRT and activity). The univariate analyses included DRT or activity as dependent variable and animal characteristic or health event, day relative to calving, and the interaction between animal characteristics and day relative to calving or the interaction between health event and day relative to calving as independent variables. A multivariate analysis was used to identify the most important animal characteristics and health events associated with DRT and activity. The multivariate models included parity, calf sex, twin birth, stillbirth, subclinical hypocalcemia, RFM, metritis, SCK, and day relative to calving as independent variables. Furthermore, the multivariate models included the interaction between each of the items (parity, calf sex, twin birth, stillbirth, subclinical hypocalcemia, RFM, metritis, SCK) and days relative to calving as independent variables. Finally, pen in which cows were housed, week of calving, BCS and locomotion score at enrollment, and number of days a cow stayed in the prepartum pen before calving were included in the multivariate model as independent variables. Independent variables with $P>0.10$ were manually removed from the model until only independent variables with $P \leq$ 0.10 remained in the model.

Correlations were considered as weak, moderate, and high when $\mathrm{r}<0.3, \mathrm{r}=0.31-0.5$, and $\mathrm{r}>0.5$, respectively. Statistical significance was defined as $P \leq 0.05$ and statistical tendencies as $0.05<P \leq 0.10$. In the analysis of repeated measures, differences in means between 2 populations within a day were evaluated using the $t$-test.

\section{RESULTS}

The percentage of male calves and twin births were $54.4 \%(161 / 296)$ and $7.4 \%(22 / 296)$, respectively. The incidences of stillbirth, RFM, metritis, subclinical hypocalcemia, and SCK were $6.1 \%(18 / 296), 13.2 \%$ (39/296), $21.2 \%(62 / 293), 37.8 \%(94 / 249)$, and $12.7 \%$
$(32 / 253)$, respectively. It is important to note that the weekly sampling and exam schedule adopted in the current experiment - despite being widely adopted by other research groups and the dairy industry-may result in some inaccuracies in the diagnosis of diseases and might not be sufficient to identify sudden changes in concentrations of metabolites. The average daily THI was $58.6 \pm 0.7$ (range: 28.9 to 80.6 ) and the average daily percentage of 2 -h intervals with THI $>68$ was 22.8 $\pm 0.1 \%$ (range: 0 to $100 \%$ ). Average milk yield in the first 90 DIM were $37.60 \pm 0.63$ and $47.51 \pm 0.60 \mathrm{~kg} / \mathrm{d}$ for primiparous and multiparous cows, respectively.

\section{Association Between Prepartum and Postpartum DRT and Activity}

Prepartum DRT was strongly correlated with postpartum DRT according to the simple correlation ( $\mathrm{r}$ $=0.60,95 \% \mathrm{CI}=0.53,0.67 ; P<0.01)$ and partial correlation $(\mathrm{r}=0.58 ; P<0.01)$ analyses. Similarly, prepartum activity was strongly correlated with postpartum activity (correlation $\mathrm{r}=0.69,95 \% \mathrm{CI}=0.62$, 0.74; $P<0.01$; partial correlation: $\mathrm{r}=0.65 ; P<0.01$ ).

\section{Association Between Milk Yield and DRT and Activity}

Average milk yield in the first 90 DIM was weakly correlated with average prepartum DRT (correlation: $\mathrm{r}$ $=0.27,95 \% \mathrm{CI}=0.15,0.37 ; P<0.01$; partial correlation: $\mathrm{r}=0.14 ; P=0.02$ ). On the other hand, 90dMilk was moderately correlated with average postpartum DRT (correlation: $\mathrm{r}=0.42,95 \% \mathrm{CI}=0.32,0.52 ; P<$ 0.01 ; partial correlation: $\mathrm{r}=0.35 ; P<0.01)$. Although there was no $(\mathrm{r}=-0.08,95 \% \mathrm{CI}=-0.19,0.04 ; P=$ 0.21 ) correlation between 90dMilk and average prepartum activity, the partial correlation analysis demonstrated a tendency for 90dMilk and average prepartum activity to be weakly correlated $(\mathrm{r}=0.11 ; P=0.06)$. On the other hand, average postpartum activity was not correlated with 90dMilk (correlation: $\mathrm{r}=-0.10$, $95 \% \mathrm{CI}=-0.22,0.02 ; P=0.11$; partial correlation: $\mathrm{r}$ $=0.05 ; P=0.39$ ).

\section{Correlation Among NEFA, BHBA, Ca, and Haptoglobin and DRT and Activity}

There was a weak correlation between $\mathrm{Ca}$ concentration and DRT (correlation: $\mathrm{r}=0.14,95 \% \mathrm{CI}=$ $0.02,0.26 ; P=0.03$; partial correlation: $\mathrm{r}=0.15 ; P$ $=0.02)$. Calcium concentration and activity were not correlated $(\mathrm{r}=0.09,95 \% \mathrm{CI}=-0.04,0.21 ; P=0.17)$. Concentration of NEFA was weakly correlated with DRT (correlation: $\mathrm{r}=-0.27,95 \% \mathrm{CI}=-0.32,-0.22$; $P<0.01$; partial correlation: $\mathrm{r}=-0.27 ; P<0.01$ ). 
Although according to the correlation analysis, NEFA concentration and activity were weakly correlated $(\mathrm{r}=$ $0.09,95 \% \mathrm{CI}=0.04,0.15 ; P<0.01)$, NEFA concentration and activity were not correlated according to the partial correlation analysis $(\mathrm{r}=-0.002 ; P=0.93)$. The correlation analysis indicated a weak correlation between BHBA concentration and DRT $(\mathrm{r}=0.08,95 \%$ $\mathrm{CI}=0.004,0.15 ; P=0.04$ ) but according to the partial correlation analysis, there was no correlation between BHBA concentration and DRT $(\mathrm{r}=0.001 ; P=0.98)$. We detected a weak correlation between BHBA concentration and activity (correlation: $\mathrm{r}=-0.19,95 \%$ $\mathrm{CI}=-0.26,-0.12 ; P<0.01 ;$ partial correlation: $\mathrm{r}$ $=-0.14 ; P<0.01)$. Haptoglobin concentration was weakly correlated with DRT (correlation: $\mathrm{r}=-0.19$, 95\% CI $=-0.25,-0.14 ; P<0.01$; partial correlation: $\mathrm{r}$ $=-0.18 ; P<0.01)$. Although according to the correlation analysis, haptoglobin concentration and activity were not correlated $(\mathrm{r}=-0.03,95 \% \mathrm{CI}=-0.08,0.03$; $P=0.33$ ), according to the partial correlation analysis, haptoglobin concentration was weakly correlated with activity $(\mathrm{r}=-0.07 ; P=0.02)$.

\section{Associations Between Health Disorders and DRT}

Results of the univariate analysis referent to DRT during the prepartum and postpartum periods are described in Table 1. Although occurrence of twins was not $(P=0.67)$ associated with prepartum DRT, cows that delivered twins had $(P<0.01)$ reduced DRT during the postpartum period (Figure 1). Animals that delivered stillborn calves had reduced DRT during the prepartum $(P=0.01)$ and postpartum $(P=0.01)$ periods (Figure 2). Prepartum DRT of cows diagnosed with subclinical hypocalcemia and healthy cows were not $(P=0.22)$ different (Figure 3$)$. Although subclinical hypocalcemia was not $(P=0.87)$ associated with postpartum DRT, the interaction between occurrence of subclinical hypocalcemia and day relative to calving was $(P<0.01)$ associated with postpartum DRT. On the day of calving $(P<0.01)$ and $3 \mathrm{~d}$ after calving $(P=0.08)$, cows with subclinical hypocalcemia had and tended to have, respectively, reduced DRT than normocalcemic cows. Occurrence of RFM was not $(P$ $=0.72$ ) associated with DRT during the prepartum period but the interaction between occurrence of RFM and day relative to calving was $(P=0.05)$ associated with prepartum DRT (Figure 4). Similarly, RFM was not $(P=0.14)$ associated with postpartum DRT but the interaction between occurrence of RFM and day relative to calving was $(P<0.01)$ associated with DRT postpartum (Figure 4 ). From 2 to $8 \mathrm{~d}$ postpartum, cows with RFM had $(P<0.05)$ reduced DRT compared with healthy cows. No differences in prepartum DRT were observed between cows diagnosed with metritis and healthy cows $(P=0.47$; Figure 5$)$. Metritis $(P=0.03)$ and the interaction between metritis and day relative to calving $(P=0.02)$ were associated with postpartum DRT because from 2 to $9 \mathrm{~d}$ postpartum metritic cows had reduced DRT compared with healthy cows $(P<$ $0.05)$ and on d 10 postpartum metritic cows tended $(P$ $=0.09)$ to have reduced DRT compared with healthy cows (Figure 5). Although SCK was not associated with prepartum $(P=0.13)$ or postpartum $(P=0.37)$ DRT, the interaction between occurrence of SCK and day relative to calving was $(P<0.01)$ associated with postpartum DRT. From d 0 to 8 postpartum, cows with SCK had $(P<0.05)$ reduced DRT compared with healthy cows and on d 11, postpartum cows with SCK tended $(P=0.10)$ to have reduced DRT compared with healthy cows (Figure 6).

Results from the multivariate analysis referent to DRT during the prepartum and postpartum periods are described in Table 2. Day relative to calving was $(P<0.01)$ associated with DRT because as cows approached calving, there was a significant decrease in DRT with a nadir on d 1 . Although twin calving was not $(P=0.79)$ associated with prepartum DRT, cows delivering twins had $(P=0.04)$ reduced postpartum DRT compared with cows delivering singletons. In the

Table 1. Association among health events and daily rumination time (DRT) prepartum and postpartum according to the univariate analysis

\begin{tabular}{|c|c|c|c|c|c|c|c|c|}
\hline \multirow[b]{3}{*}{ Health event ${ }^{1}$} & \multirow{2}{*}{\multicolumn{2}{|c|}{$\begin{array}{l}\text { Differences of LSM of DRT } \\
\qquad(\min / \mathrm{d} \pm \mathrm{SEM})\end{array}$}} & \multicolumn{6}{|c|}{$P$-value } \\
\hline & & & \multicolumn{3}{|c|}{ Prepartum } & \multicolumn{3}{|c|}{ Postpartum } \\
\hline & Prepartum & Postpartum & Item & Day & Item $\times$ Day & Item & Day & Item $\times$ Day \\
\hline Twins & $9.6 \pm 22.5$ & $52.0 \pm 17.8$ & 0.67 & 0.23 & 0.86 & $<0.01$ & $<0.01$ & 0.01 \\
\hline Stillbirth & $60.9 \pm 24.1$ & $50.7 \pm 19.9$ & 0.01 & 0.06 & 0.07 & 0.01 & $<0.01$ & 0.45 \\
\hline Subclinical hypocalcemia & $16.5 \pm 13.5$ & $1.8 \pm 10.8$ & 0.22 & 0.03 & 0.11 & 0.87 & $<0.01$ & $<0.01$ \\
\hline Retained fetal membrane & $-6.3 \pm 17.2$ & $20.7 \pm 13.9$ & 0.72 & $<0.01$ & 0.05 & 0.14 & $<0.01$ & $<0.01$ \\
\hline Metritis & $10.3 \pm 14.3$ & $25.2 \pm 11.3$ & 0.47 & 0.01 & 0.46 & 0.03 & $<0.01$ & 0.02 \\
\hline Subclinical ketosis & $-27.9 \pm 18.3$ & $13.5 \pm 15.0$ & 0.13 & 0.19 & 0.69 & 0.37 & $<0.01$ & $<0.01$ \\
\hline
\end{tabular}

${ }^{1}$ Cows that presented each event were used as reference. 


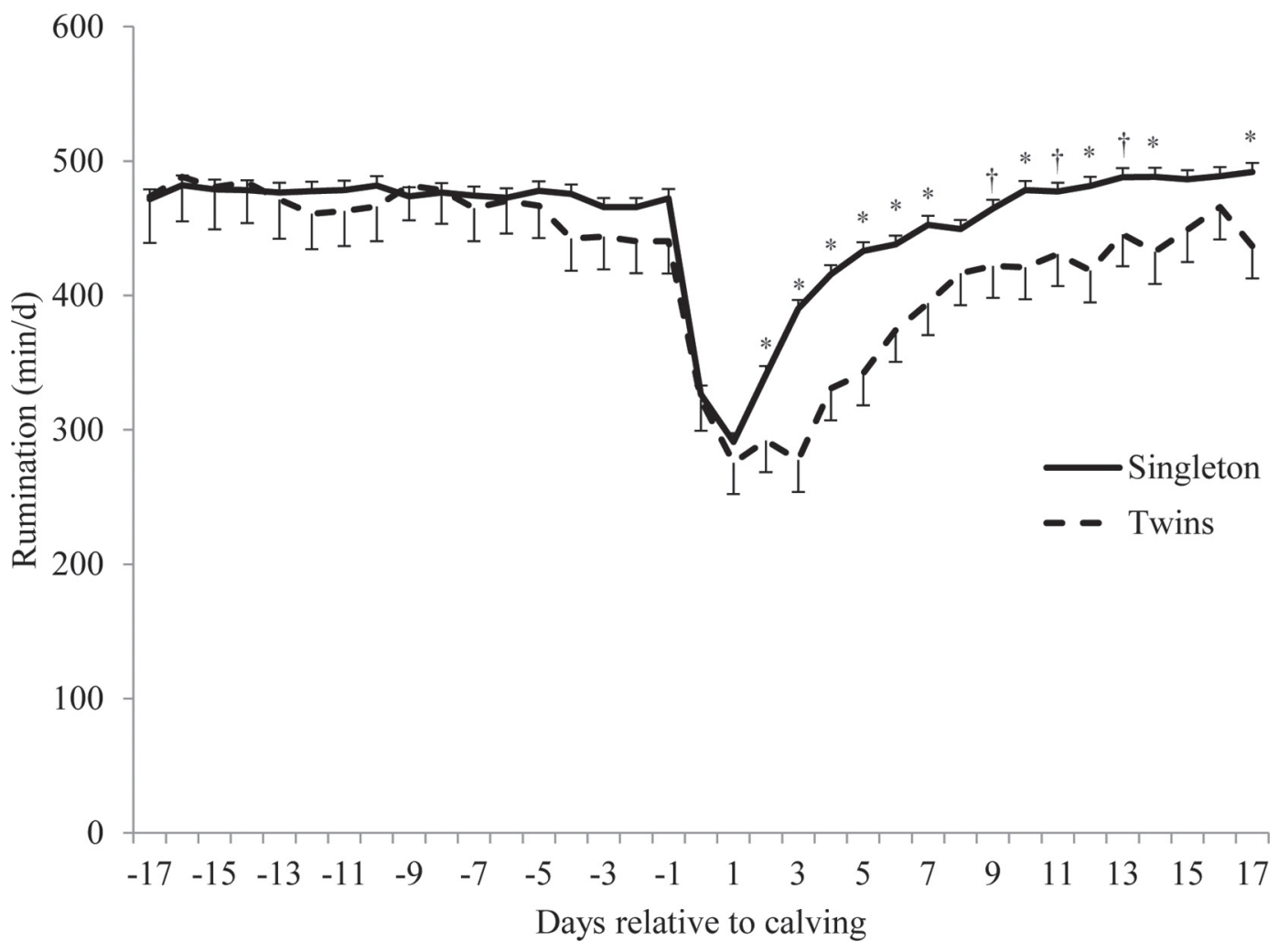

Figure 1. Association between occurrence of twins and daily rumination time. Prepartum: occurrence of twins, $P=0.67$; day relative to calving, $P=0.23$; interaction between occurrence of twins and day relative to calving, $P=0.86$. Postpartum: occurrence of twins, $P<0.01$; day relative to calving, $P<0.01$; interaction between occurrence of twins and day relative to calving, $P=0.01$. ${ }^{*}$ Within day, means differ $(P$ $<0.05)$; †within day, means tended to differ $(P<0.10)$.

postpartum period, the interaction between occurrence of twin calving and day relative to calving was $(P<$ $0.01)$ associated with DRT because on d $3,5,12,14,16$, and 17, cows delivering twins had $(P<0.05)$ reduced DRT and on d 4, 10, and 15, cows delivering twins tended $(P<0.10)$ to have to reduced DRT. Occurrence of stillbirth was not associated with prepartum $(P=$ $0.44)$ or postpartum $(P=0.42)$ DRT. The interaction between occurrence of stillbirth and day relative to calving, however, was $(P=0.02)$ associated with prepartum DRT. Prepartum $(P=0.22)$ and postpartum $(P=0.84)$ DRT were not associated with subclinical hypocalcemia. Nevertheless, the interaction between occurrence of subclinical hypocalcemia and day relative to calving was associated with prepartum $(P<0.01)$ and postpartum $(P<0.01)$ DRT. Daily rumination time of cows with subclinical hypocalcemia was $(P<$ 0.05 ) reduced on $\mathrm{d}-16,-13$, and -11 and tended $(P$ $<0.10)$ to be reduced on $\mathrm{d}-12$. Cows with subclinical hypocalcemia had $(P<0.01)$ and tended to have $(P=$ $0.10)$ reduced DRT on $\mathrm{d} 1$ and 3 postpartum, respectively. No differences were observed in prepartum $(P=$ $0.61)$ and postpartum $(P=0.36)$ DRT between cows that had RFM and healthy cows. On the other hand, the interaction between occurrence of RFM and day relative to calving was associated with prepartum $(P=$ $0.02)$ DRT because cows with RFM tended $(P=0.07)$ to have reduced DRT on $\mathrm{d}-1$ prepartum compared with healthy cows. Similarly, the interaction between occurrence of RFM and day relative to calving was ( $P$ $<0.01$ ) associated with postpartum DRT because cows with RFM had $(P<0.05)$ reduced DRT from d 2 to 7 and on $\mathrm{d} 17$ and tended $(P=0.06)$ to have reduced DRT on d 8 compared with healthy cows. Surprisingly, cows with RFM tended $(P=0.08)$ to have greater DRT on d 16 than healthy cows. Occurrence of metritis was not associated with prepartum $(P=0.22)$ or postpartum $(P=0.22)$ DRT. Although SCK was not associated with prepartum $(P=0.29)$ or postpartum $(P=$ $0.11)$ DRT, the interaction between occurrence of SCK and day relative to calving was $(P<0.01)$ associated with postpartum DRT. On d 0 , cows with SCK had ( $P$ $=0.01$ ) greater DRT compared with normal cows but from d 8 to 17 postpartum, DRT of cows with SCK was $(P<0.05)$ reduced compared with that of healthy cows. 


\section{Associations Between Health Disorders and Daily Activity}

Results of the univariate analysis referent to activity during the prepartum and postpartum periods are described in Table 3. Cows that delivered twins had reduced activity during the prepartum $(P=0.02)$ and postpartum $(P<0.01)$ periods (Figure 7$)$. Although animals that delivered stillborn calves had greater $(P=$ 0.02 ) prepartum activity than those that delivered live calves, postpartum activity was not $(P=0.80)$ associated with stillbirth (Figure 8 ). The interaction between occurrence of stillbirth and day relative to calving was $(P=0.03)$ associated with activity. Subclinical hypocalcemia was not associated with prepartum $(P=0.14)$ and postpartum $(P=0.91)$ activity. Cows diagnosed with RFM tended $(P=0.06)$ to have reduced activity prepartum and had $(P<0.01)$ reduced activity postpartum (Figure 9). The interaction between occurrence of RFM and day relative to calving was $(P<0.01)$ associated with activity during the postpartum period. Cows with RFM had $(P<0.05)$ reduced activity from d 1 to 7 and on d 10 and 11 compared with healthy cows. Activity of cows with RFM tended $(P<0.10)$ to be reduced on d 8 and 9 compared with that of healthy cows. No association between occurrence of metritis and prepartum activity was observed $(P=0.68)$ but cows diagnosed with metritis had reduced $(P=$ 0.04) postpartum activity compared with healthy cows (Figure 10). From d 2 to 5, cows with metritis had ( $P$ $<0.05)$ reduced activity and on d 1, 7, 10,11, and 12 , metritic cows tended $(P<0.10)$ to have reduced activity. Although occurrence of SCK was not $(P=0.96)$ associated with prepartum activity, cows diagnosed with SCK had $(P=0.05)$ reduced postpartum activity (Figure 11). Cows with SCK had $(P<0.05)$ reduced activity from d 7 to 11 and on d 13, 15, 16, and 17 and tended $(P=0.09)$ to have reduced activity on $\mathrm{d} 12$.

Results of the multivariate analysis referent to activity during the prepartum and postpartum periods are described in Table 4. Day relative to calving had $(P<$ 0.01 ) a significant effect on activity because, as cows approached calving, there was a significant increase in activity with a peak of activity on $\mathrm{d} 1$. Cows that delivered twins had $(P=0.02)$ reduced activity prepartum compared with animals that delivered singletons. The interaction between occurrence of twins and day relative to calving was $(P<0.01)$ associated with activity

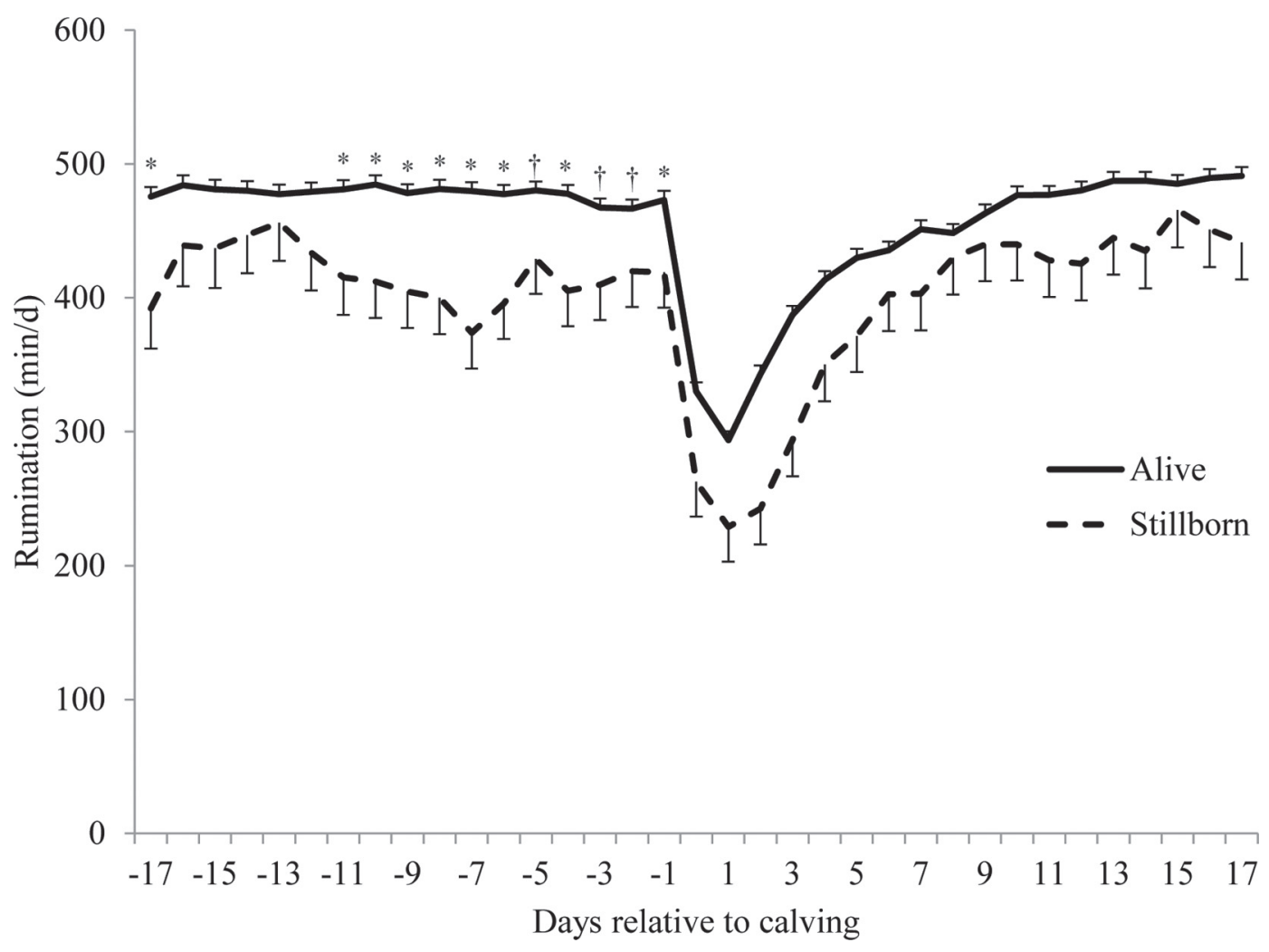

Figure 2. Association between occurrence of stillbirth and daily rumination time. Prepartum: occurrence of stillbirth, $P=0.01$; day relative to calving, $P=0.06$; interaction between occurrence of stillbirth and day relative to calving, $P=0.07$. Postpartum: occurrence of stillbirth, $P$ $=0.01$; day relative to calving, $P<0.01$; interaction between occurrence of stillbirth and day relative to calving, $P=0.45$. Within day, means differ $(P<0.05)$; †within day, means tended to differ $(P<0.10)$. 


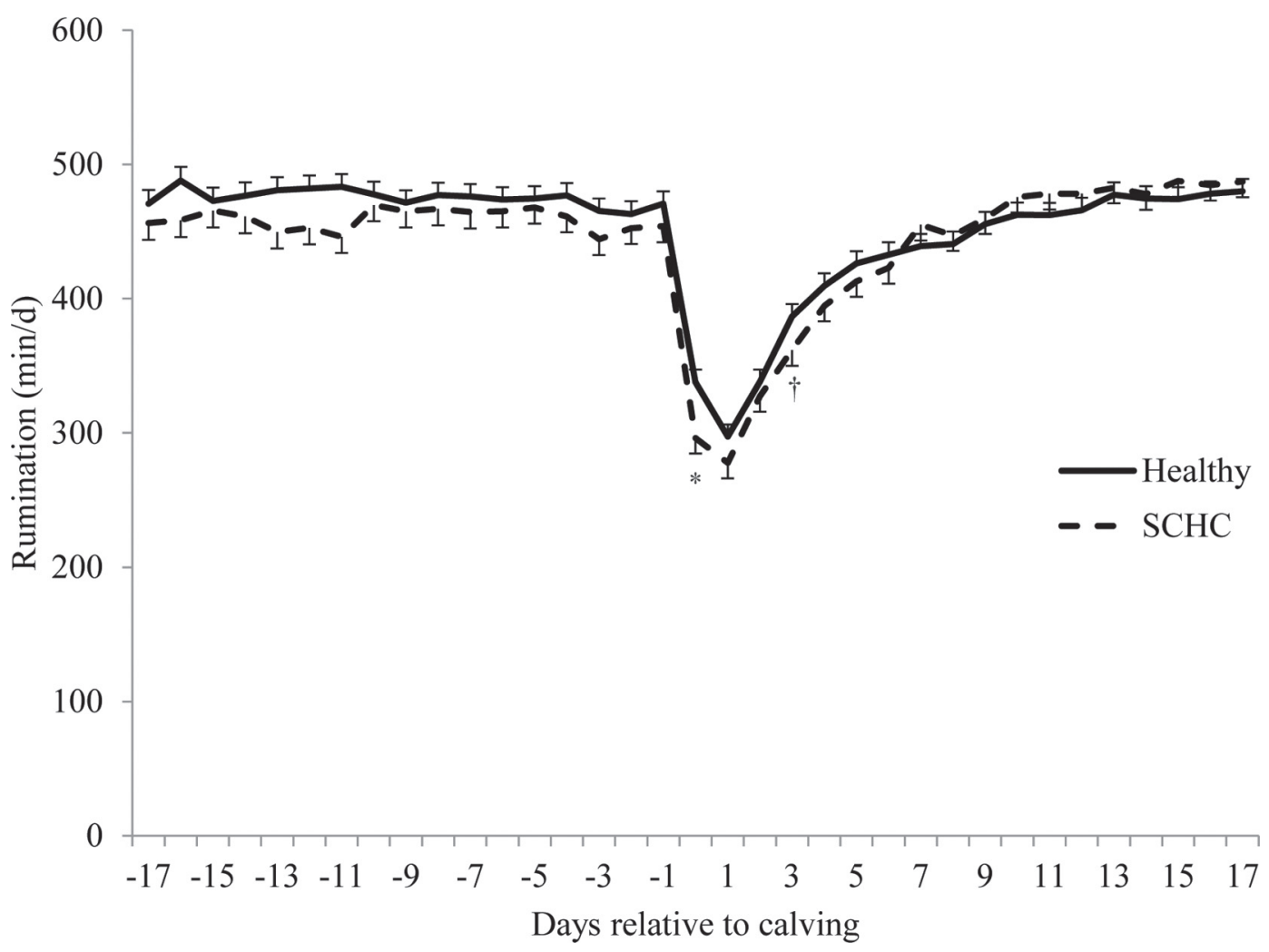

Figure 3. Association between occurrence of subclinical hypocalcemia (SCHC) and daily rumination time. Prepartum: occurrence of SCHC, $P=0.22$; day relative to calving, $P=0.03$; interaction between occurrence of SCHC and day relative to calving, $P=0.11$. Postpartum: occurrence of SCHC, $P=0.87$; day relative to calving, $P<0.01$; interaction between occurrence of SCHC and day relative to calving, $P<0.01$. *Within day, means differ $(P<0.05)$; †within day, means tended to differ $(P<0.10)$.

prepartum because on $\mathrm{d}-16,-15,-14,-12$, and -11 , cows delivering twins had $(P<0.05)$ reduced activity and on $\mathrm{d}-17$ and -4 , cows delivering twins tended $(P<0.10)$ to have reduced activity. We detected no $(P=0.74)$ difference in activity postpartum between animals delivering singletons and twins. On the other hand, animals delivering stillborn calves had $(P<0.01)$ increased prepartum activity compared with animals delivering live calves but occurrence of stillbirth was not $(P=0.17)$ associated with postpartum activity. Occurrence of subclinical hypocalcemia was not associated with prepartum $(P=0.34)$ or postpartum $(P=$ $0.47)$ activity. Occurrence of RFM was not $(P=0.31)$ associated with prepartum activity, but postpartum activity tended $(P=0.08)$ to be reduced among cows diagnosed with RFM compared with healthy cows. The interaction between occurrence of RFM and activity was $(P<0.01)$ associated with activity because cows with RFM had $(P<0.01)$ reduced activity from $\mathrm{d} 1$ to 5 and tended $(P=0.10)$ to have reduced activity on $\mathrm{d} 6$. Occurrence of metritis was not associated with prepartum $(P=0.56)$ or postpartum $(P=0.24)$ activity. Similarly, occurrence of SCK was not associated with prepartum $(P=0.28)$ or postpartum $(P=0.45)$ activity. The interaction between occurrence of SCK and day relative to calving, however, was $(P<0.01)$ associated with postpartum activity. Cows with SCK had $(P=0.03)$ reduced activity on $\mathrm{d} 10$ and tended $(P<0.10)$ to have reduced activity on $\mathrm{d} 8,15$, and 16 .

\section{DISCUSSION}

In the current cohort observational experiment, DRT and activity patterns of periparturient animals presenting different health disorders were described. Although rumination time within a 2 -h period or within a day may not accurately reflect total DMI within these periods (Schirmann et al., 2012), decreases in DRT over time are observed when decreases in DMI are observed, particularly around the time of calving (Schirmann et al., 2013). Thus, variations in DRT may be used as a proxy for variations in DMI.

The strong correlation between prepartum and postpartum DRT reported herein is similar to the correlation between prepartum and postpartum DMI reported in several experiments (reviewed by Grummer et al., 2004). According to the review by Grummer et al. (2004), however, the correlation between prepartum 


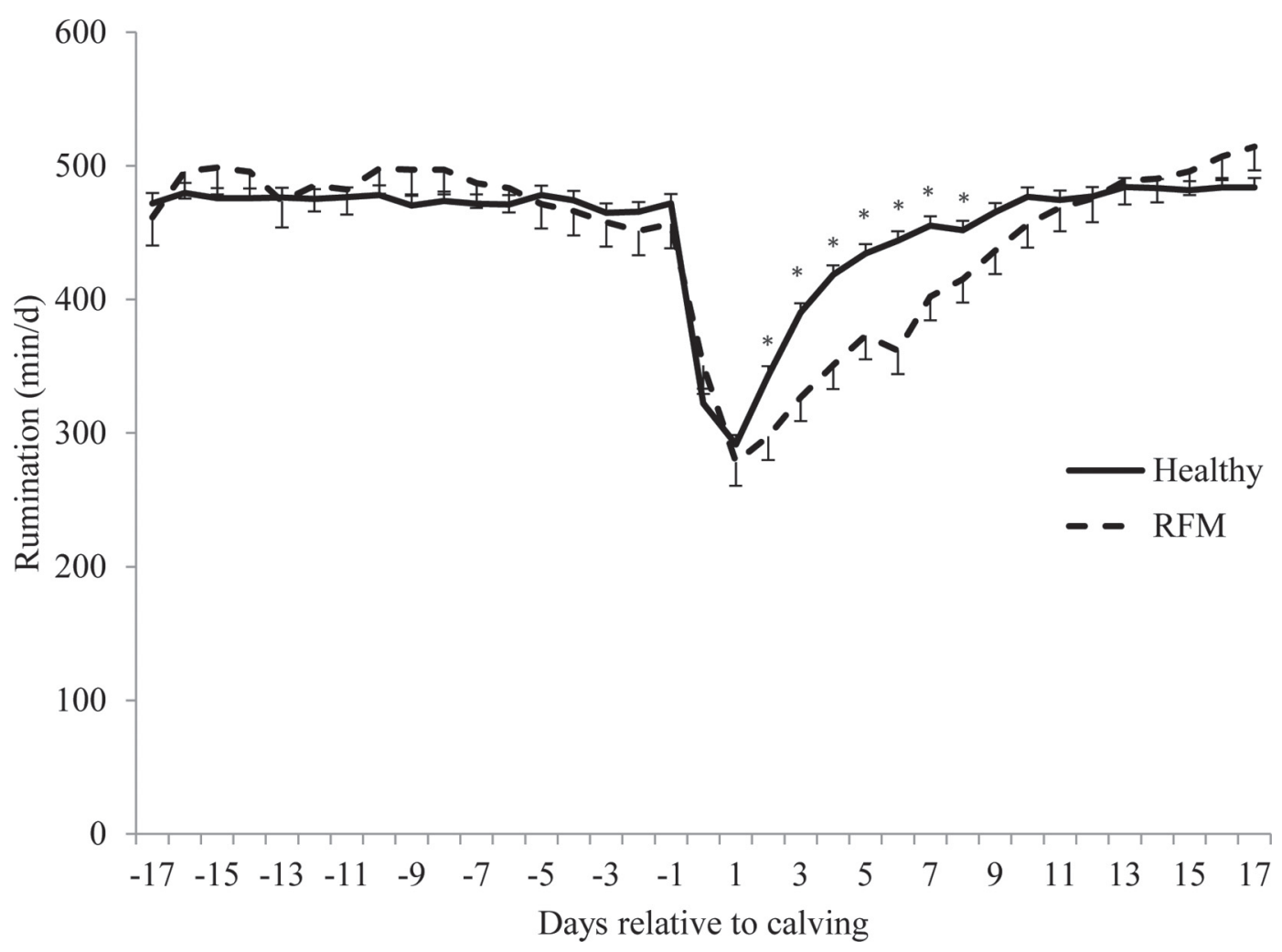

Figure 4. Association between occurrence of retained fetal membranes (RFM) and daily rumination time. Prepartum: occurrence of RFM, $P$ $=0.72$; day relative to calving, $P<0.01$; interaction between occurrence of RFM and day relative to calving, $P=0.05$. Postpartum: occurrence of RFM, $P=0.14$; day relative to calving, $P<0.01$; interaction between occurrence of RFM and day relative to calving, $P<0.01$. ${ }^{*}$ Within day, means differ $(P<0.05)$.

and postpartum DMI seems to depend more on the genetic potential of the animal than on the physical or chemical attributes of the diet. On the other hand, Mertens (1997) demonstrated that changes in processing of roughage that result in finer particles reduce the rate of mastication of dairy cows regardless of the chemical composition of the diet. Experiments are necessary to determine how variability in particle size and physical effective fiber affect DRT of periparturient dairy cows. Interestingly, in the current experiment, we observed a strong correlation between prepartum and postpartum average activity. We are unaware of previous experiments that have demonstrated a similar correlation between prepartum and postpartum activity. Additional experiments are necessary to determine what animal, environmental, and nutritional factors explain prepartum and postpartum DRT and activity.

Daily rumination time was weakly correlated with Ca concentration within $72 \mathrm{~h}$ after calving. Smooth muscle (e.g., rumen) and skeletal muscle contractions depend on the availability of Ca (Murray et al., 2008). Among cows with subclinical hypocalcemia, a reduced DRT was observed on the day of calving and $3 \mathrm{~d}$ later based on the univariate analysis. Soon thereafter, however, no differences were observed between normocalcemic cows and cows with subclinical hypocalcemia. Cows induced to develop hypocalcemia have reduced DMI (Martinez et al., 2014). Thus, it is likely that in the first hours following parturition, the reduced availability of $\mathrm{Ca}$ and the likely reduced DMI of cows diagnosed with subclinical hypocalcemia led to decreased DRT. The weak correlation between $\mathrm{Ca}$ concentration and DRT and the small differences in mean DRT between cows with subclinical hypocalcemia and normocalcemic cows indicate that DRT based on a single time point may not be accurate for diagnosis of subclinical hypocalcemia. It is not clear why we found no association between subclinical hypocalcemia and activity despite skeletal muscle's dependence on Ca for contraction. In an observational experiment, however, minor changes in standing time in the week before and the week after calving were reported for cows diagnosed with hypocalcemia (Jawor et al., 2012).

We detected a weak negative correlation between NEFA concentration and DRT and found no correlation between BHBA concentration and DRT. This suggests that DRT is not representative of metabolic state within a day or that the frequency of sampling used 


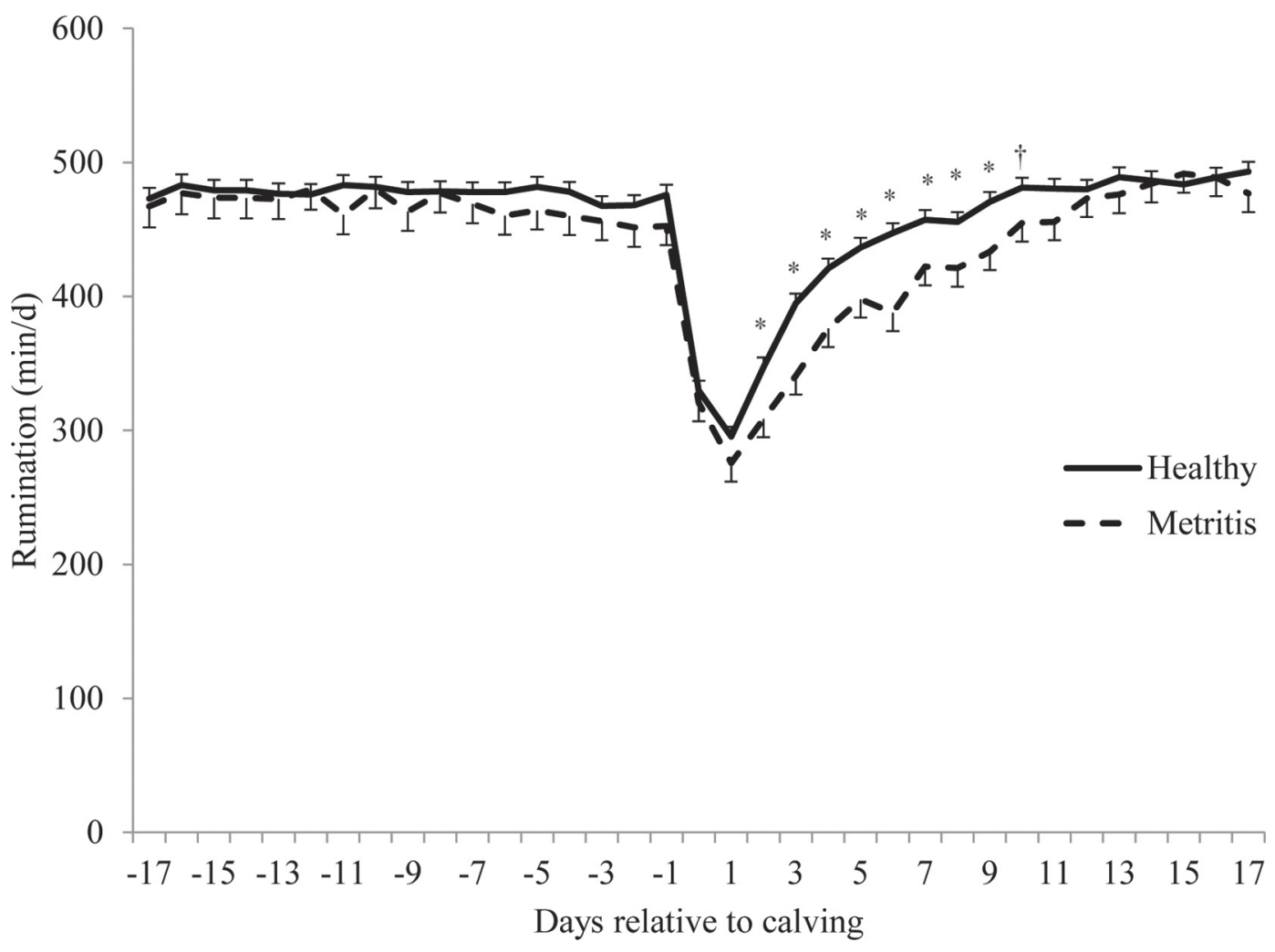

Figure 5. Association between occurrence of metritis and daily rumination time. Prepartum: occurrence of metritis, $P=0.47$; day relative to calving, $P=0.01$; interaction between occurrence of metritis and day relative to calving, $P=0.46$. Postpartum: occurrence of metritis, $P=$ 0.03; day relative to calving, $P<0.01$; interaction between occurrence of metritis and day relative to calving, $P=0.02$. ${ }^{*}$ Within day, means differ $(P<0.05)$; †within day, means tended to differ $(P<0.10)$.

in the current experiment may have been inadequate to identify subtle changes in metabolic status. Cows diagnosed with SCK, however, had reduced DRT from calving to $8 \mathrm{~d}$ postpartum and reduced activity from $\mathrm{d}$ 7 to 17 postpartum, except on d 14 postpartum, compared with healthy cows. Others have demonstrated significant changes in feeding behavior before and after the diagnosis of ketosis (González et al., 2008; Goldhawk et al., 2009). Furthermore, Edwards and Tozer (2004) demonstrated that cows diagnosed with ketosis and metabolic disorders had reduced steps per hour during the postpartum period compared with healthy cows. The usefulness of DRT and activity data to aid in the diagnosis of SCK is likely dependent on screening practices currently adopted in the herd.

The partial correlation analysis identified a weak negative correlation between haptoglobin concentration and DRT. When the prepartum and the postpartum data were analyzed separately, there was no correlation between prepartum haptoglobin concentration and prepartum DRT but there was a weak negative correlation between postpartum haptoglobin concentration and postpartum DRT (data not shown). We are unaware of experiments that have evaluated the association be- tween haptoglobin concentration and DRT. To restore homeostasis and protect normal tissue, acute phase proteins such as haptoglobin are produced in response to tissue injury, infection, or inflammation (Baumann and Gauldie, 1994). In the current experiment, cows diagnosed with RFM and metritis had haptoglobin concentrations 14 and $20 \%$ greater, respectively, than healthy cows during the postpartum period (data not shown). Therefore, the weak negative correlation between haptoglobin concentration and DRT during the postpartum period might be confounded by the occurrence of postpartum uterine disorders and other inflammatory processes.

Unexpectedly, cows that delivered twins had similar DRT during the prepartum period compared with cows that delivered singletons. The reduced postpartum DRT among cows that delivered twins compared with cows delivering singletons was somewhat expected because occurrence of twins increases the risk of uterine (e.g., RFM and metritis) and metabolic diseases (Benzaquen et al., 2007; Dubuc et al., 2010). Silva-del-Río et al. (2010) demonstrated that, despite the fact that cows that delivered twins had reduced energy balance during the prepartum period compared with cows that deliv- 


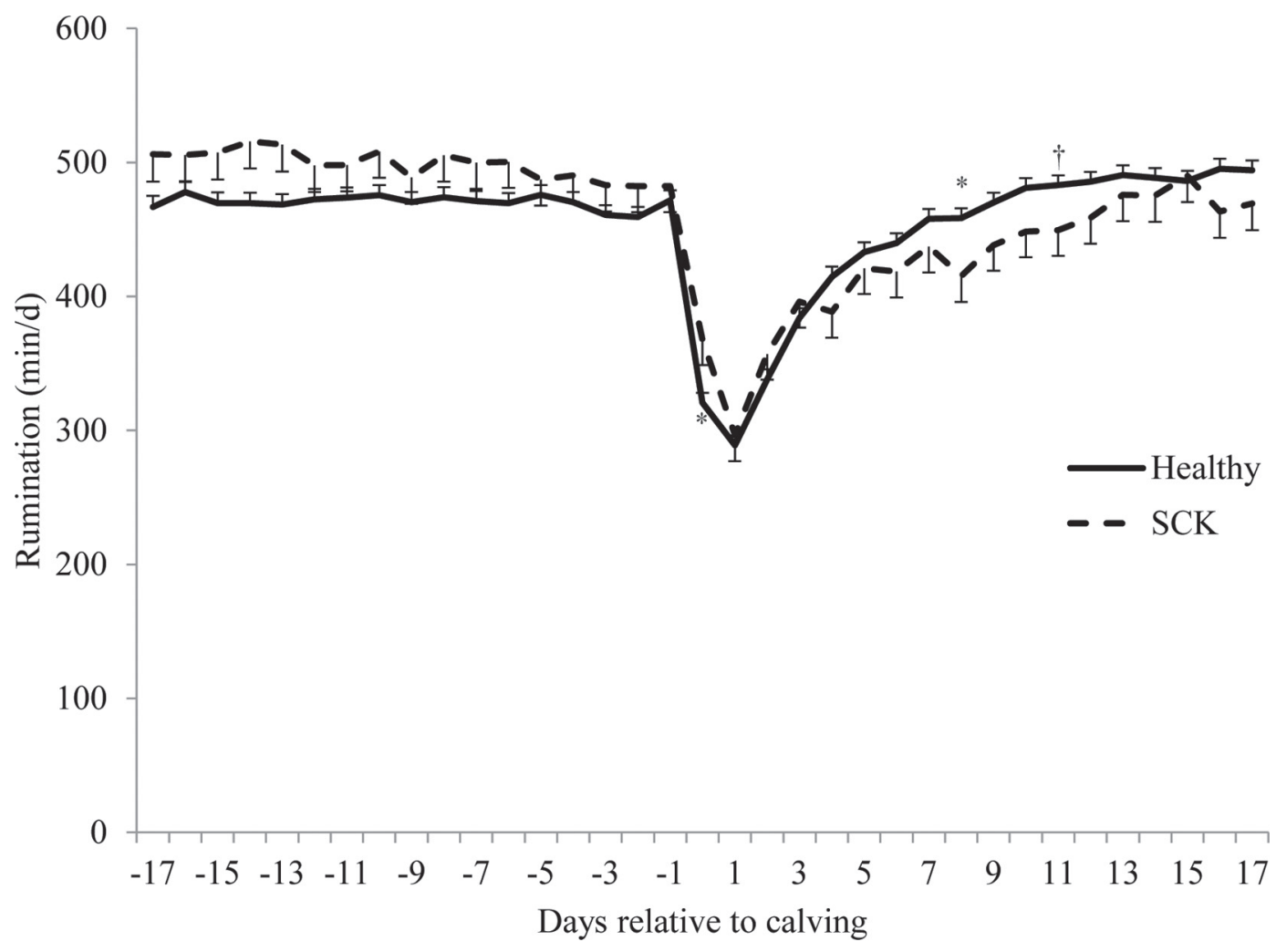

Figure 6. Association between occurrence of subclinical ketosis (SCK) and daily rumination time. Prepartum: occurrence of SCK, $P=0.13$; day relative to calving, $P=0.19$; interaction between occurrence of SCK and day relative to calving, $P=0.69$. Postpartum: occurrence of SCK; $P=0.37$, day relative to calving; $P<0.01$, interaction between occurrence of SCK and day relative to calving, $P<0.01 .{ }^{*}$ Within day, means differ $(P<0.05)$; †within day, means tended to differ $(P<0.10)$.

Table 2. Daily rumination time (DRT) according to animal characteristics and health events based on the multivariate analysis ${ }^{1}$

\begin{tabular}{|c|c|c|c|c|c|c|c|c|}
\hline Item & & & \multicolumn{6}{|c|}{$P$-value } \\
\hline Number of calves & & & 0.79 & 0.66 & 0.86 & 0.04 & $<0.01$ & $<0.01$ \\
\hline Singleton & $449.8 \pm 23.7$ & $406.7 \pm 11.1$ & & & & & & \\
\hline Twins & $441.8 \pm 33.3$ & $359.8 \pm 21.7$ & & & & & & \\
\hline Yes & $418.7 \pm 30.0$ & $417.9 \pm 26.5$ & & & & & & \\
\hline Subclinical hypocalcemia & & & 0.22 & 0.66 & $<0.01$ & 0.84 & $<0.01$ & $<0.01$ \\
\hline No & $439.4 \pm 18.0$ & $384.4 \pm 14.0$ & & & & & & \\
\hline Yes & $423.2 \pm 17.7$ & $382.2 \pm 14.2$ & & & & & & \\
\hline Retained fetal membrane & & & 0.61 & 0.66 & 0.02 & 0.36 & $<0.01$ & $<0.01$ \\
\hline No & $435.8 \pm 15.8$ & $390.9 \pm 14.7$ & & & & & & \\
\hline Yes & $426.8 \pm 22.0$ & $375.7 \pm 16.3$ & & & & & & \\
\hline Yes & $458.7 \pm 25.5$ & $369.9 \pm 18.7$ & & & & & & \\
\hline
\end{tabular}

${ }^{1}$ Variables that were retained in the final multivariate analysis models: Prepartum $=$ parity, days relative to calving, stillbirth, stillbirth $\times$ days relative to calving, retained fetal membrane, retained fetal membrane $\times$ days relative to calving, subclinical hypocalcemia, and subclinical hypocalcemia $\times$ days relative to calving. Postpartum $=$ parity, day, parity $\times$ days relative to calving, twinning, twinning $\times$ days relative to calving, retained fetal membrane, retained fetal membrane $\times$ days relative to calving, subclinical hypocalcemia, and subclinical hypocalcemia $\times$ days relative to calving, subclinical ketosis, subclinical ketosis $\times$ days relative to calving, locomotion score at $3 \mathrm{~d}$ relative to calving. 
Table 3. Association among animal factors and health events and daily activity prepartum and postpartum according to the univariate analysis

\begin{tabular}{|c|c|c|c|c|c|c|c|c|}
\hline Item $^{1}$ & \multicolumn{2}{|c|}{$\begin{array}{l}\text { Differences of LSM of activity } \\
\quad(\text { arbitrary unit } \pm \text { SEM) }\end{array}$} & \multicolumn{6}{|c|}{$P$-value } \\
\hline Twins & $34.9 \pm 15.4$ & $56.2 \pm 20.1$ & 0.02 & $<0.01$ & 0.05 & $<0.01$ & $<0.01$ & $<0.01$ \\
\hline Stillbirth & $-38.0 \pm 16.7$ & $5.9 \pm 22.7$ & 0.02 & $<0.01$ & 0.71 & 0.80 & 0.02 & 0.03 \\
\hline Subclinical hypocalcemia & $-13.8 \pm 9.2$ & $-1.5 \pm 12.3$ & 0.14 & $<0.01$ & 0.22 & 0.91 & $<0.01$ & 0.68 \\
\hline Subclinical ketosis & $0.7 \pm 13.5$ & $34.4 \pm 17.6$ & 0.96 & $<0.01$ & 0.11 & 0.05 & $<0.01$ & $<0.01$ \\
\hline
\end{tabular}

${ }^{1}$ Cows that presented each event were used as reference.

ered singletons, only minor differences in DMI were observed during the prepartum period. It is possible that the small number of cows delivering twins in the current experiment was insufficient to detect statistical differences in prepartum DRT between cows delivering twins and singletons. Although according to the univariate analysis, cows delivering twins had reduced activity during the prepartum and postpartum periods, only prepartum activity differed between cows delivering twins and singletons according to the multivariate analysis. This indicates that the reduced postpartum activity of cows that delivered twins may be confounded by infectious and metabolic diseases to which they are more predisposed compared with cows delivering singletons. The reduced activity of cows carrying twins during the prepartum period, on the other hand, may indicate discomfort.

Although the univariate analysis suggested that DRT differed between cows delivering stillborn and live calves, the lack of difference in DRT according to the multivariate analysis suggests differences in DRT between cows delivering stillborn and live calves may be a consequence of other diseases associated with stillbirth. On the other hand, according to the multivariate analysis, cows delivering stillborn calves had reduced activity during the prepartum period but not during the post-

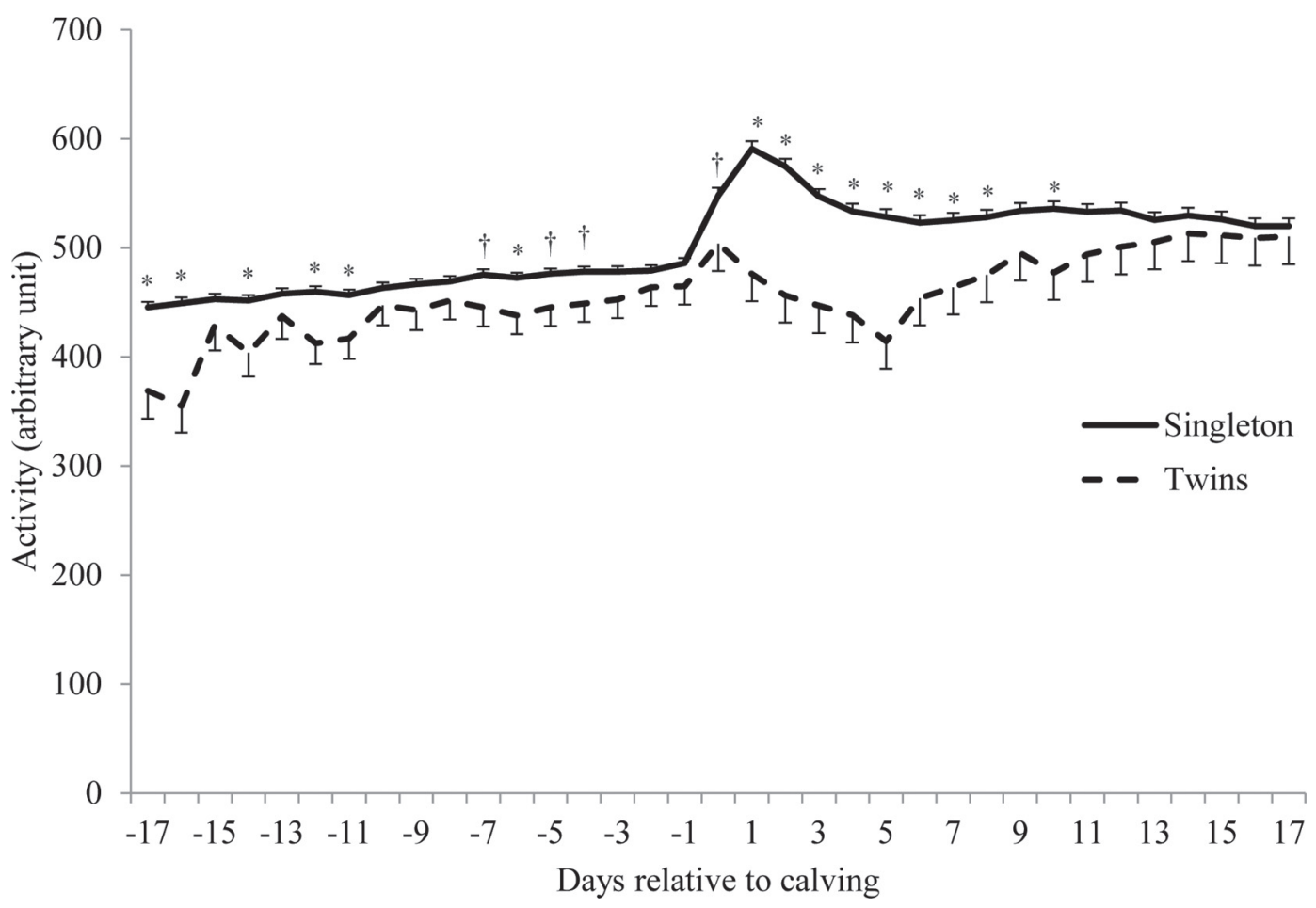

Figure 7. Association between occurrence of twins and daily activity. Prepartum: occurrence of twins, $P=0.02$; day relative to calving, $P<$ 0.01; interaction between occurrence of twins and day relative to calving, $P=0.05$. Postpartum: occurrence of twins, $P<0.01$; day relative to calving, $P<0.01$; interaction between occurrence of twins and day relative to calving, $P<0.01$. ${ }^{*}$ Within day, means differ $(P<0.05)$; †within day, means tended to differ $(P<0.10)$. 
partum period. Proudfoot et al. (2009) demonstrated that DMI, feeding time, and number of standing bouts were reduced immediately before calving among cows presenting dystocia. The increased prepartum activity observed among cows delivering twins and stillborn calves and the increased number of standing bouts of dystocic cows (Proudfoot et al., 2009) suggest that cows that have twins, cows that have stillborn calves, and cows that have dystocia may be restless due to discomfort before the onset of actual calving.

The interaction between RFM and day relative to calving was associated with DRT during the prepartum and postpartum periods. Occurrence of metritis, however, was not associated with DRT. Previous experiments have demonstrated that cows diagnosed with metritis have reduced prepartum feed intake (Hammon et al., 2006; Huzzey et al., 2007). The reduced DMI is expected to cause immunosuppression (Hammon et al., 2006) through the increased severity and extent of negative energy balance. It is possible that no differences in DRT during the postpartum period were observed between healthy and metritic cows because the occurrence of metritis was confounded by the occurrence of RFM. In the current experiment, $66.7 \%$ of cows diagnosed with RFM were also diagnosed with metritis, whereas only $14.2 \%$ of cows that did not have
RFM were diagnosed with metritis. Because the aim of the current experiment was to demonstrate the association between health disorders commonly diagnosed on farm, separating cows that presented multiple diseases from those presenting only one disease did not seem appropriate. It is unclear why cows with RFM but not metritic cows presented reduced activity during the postpartum period. Although study personnel diagnosed all the diseases reported herein, it is possible that farm personnel selectively retained more cows with RFM in the hospital pen following calving, which was smaller than the pen of apparently healthy postpartum cows.

It is interesting to note that, regardless of the type of health events diagnosed, all cows had a significant decrease in DRT and a significant increase in activity within 24 to $48 \mathrm{~h}$ relative to calving. In the current experiment, animals were moved to a maternity pen at the first sign of imminent calving but the exact time of calving was not recorded. Although movement to a different pen might have affected DRT and activity, it is likely that the variability in DRT and activity on the day of calving is explained mostly by the calving itself. Schirmann et al. (2013) demonstrated that cows have a significant decrease in rumination starting approximately $48 \mathrm{~h}$ before calving, reaching a nadir by

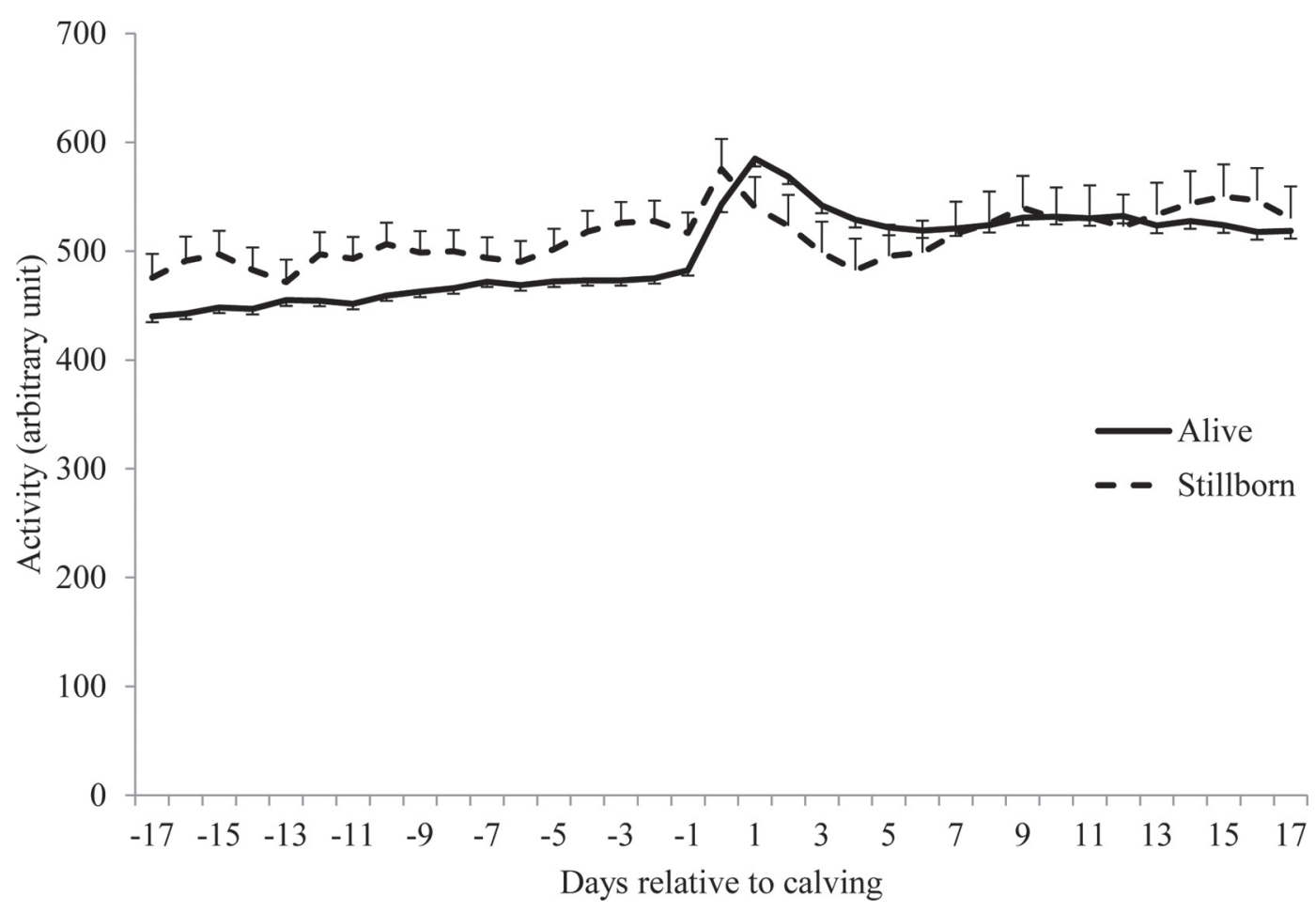

Figure 8. Association between occurrence of stillbirth and daily activity. Prepartum: occurrence of stillbirth, $P=0.02$; day relative to calving, $P<0.01$; interaction between occurrence of stillbirth and day relative to calving, $P=0.71$. Postpartum: occurrence of stillbirth, $P=0.80$; day relative to calving, $P=0.02$; interaction between occurrence of stillbirth and day relative to calving, $P=0.03$. 


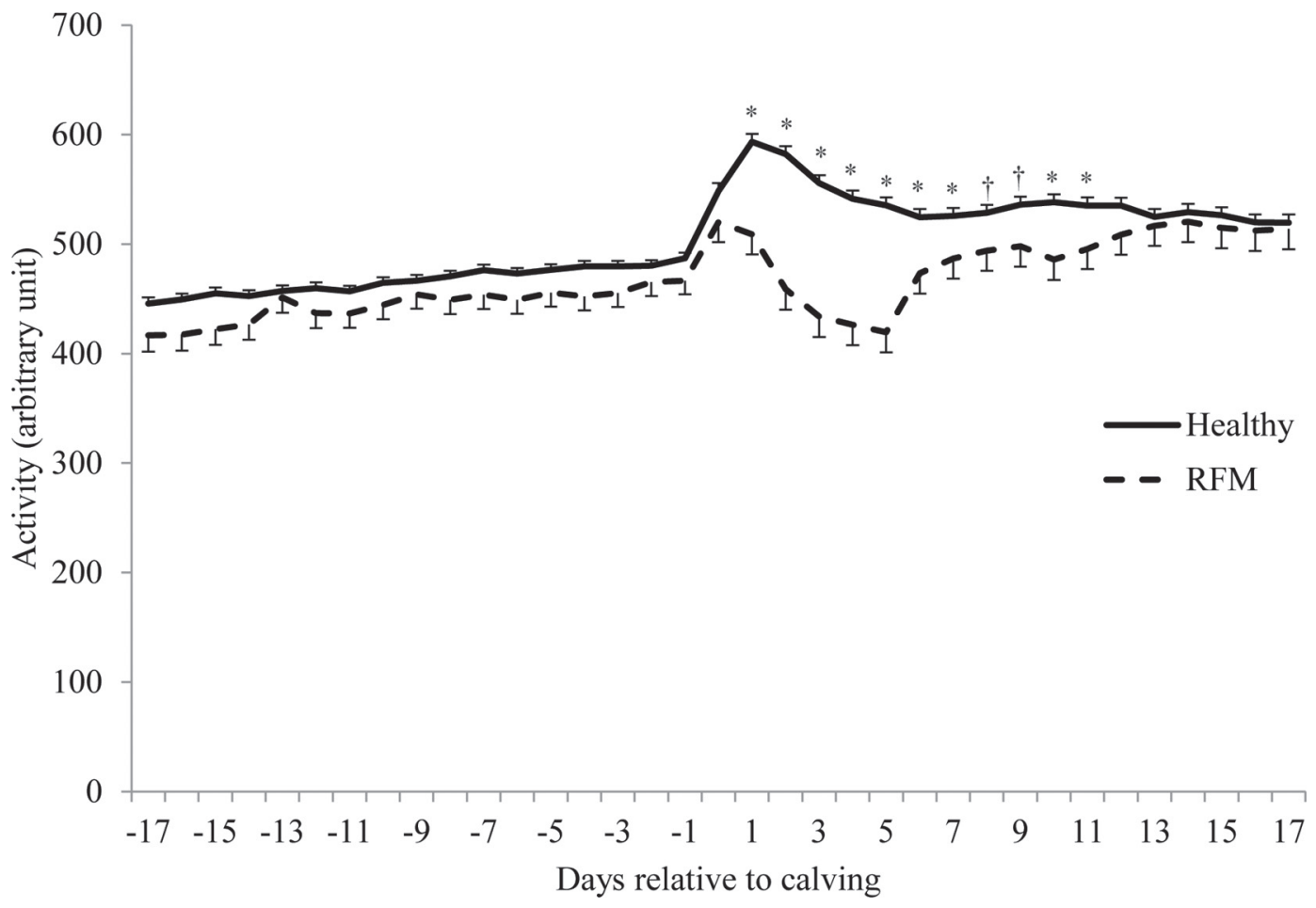

Figure 9. Association between occurrence of retained fetal membranes (RFM) and daily activity. Prepartum: occurrence of RFM, $P=0.06$; day relative to calving, $P<0.01$; interaction between occurrence of RFM and day relative to calving, $P=0.90$. Postpartum: occurrence of RFM, $P<0.01$; day relative to calving, $P<0.01$; interaction between occurrence of RFM and day relative to calving, $P<0.01$. ${ }^{*}$ Within day, means differ $(P<0.05)$; †within day, means tended to differ $(P<0.10)$.

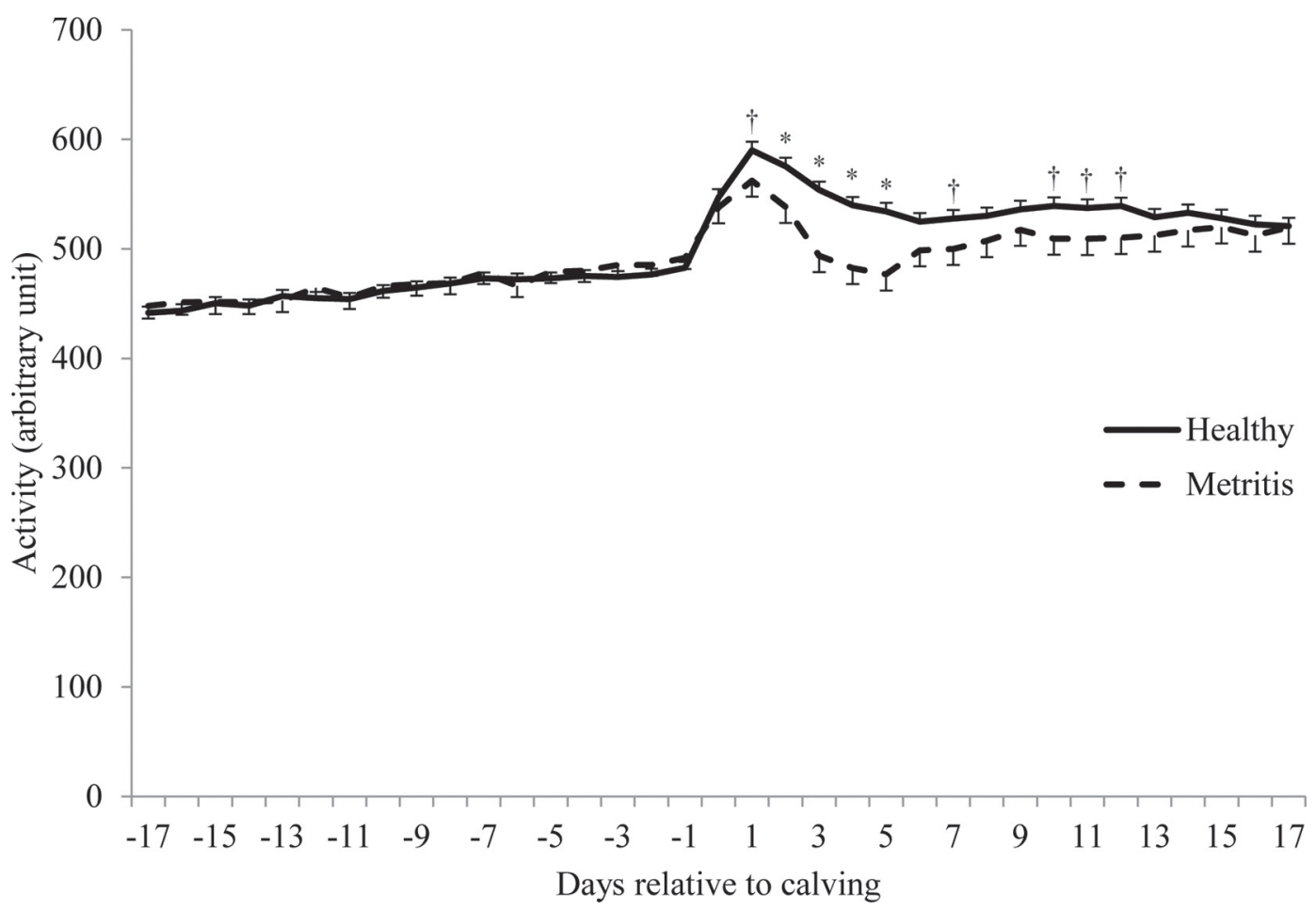

Figure 10. Association between occurrence of metritis and daily activity. Prepartum: occurrence of metritis, $P=0.68$; day relative to calving, $P<0.01$; interaction between occurrence of metritis and day relative to calving, $P=0.92$. Postpartum: occurrence of metritis, $P=0.04$; day relative to calving, $P<0.01$; interaction between occurrence of metritis and day relative to calving, $P=0.02 .{ }^{*}$ Within day, means differ $(P$ $<0.05)$; †within day, means tended to differ $(P<0.10)$. 


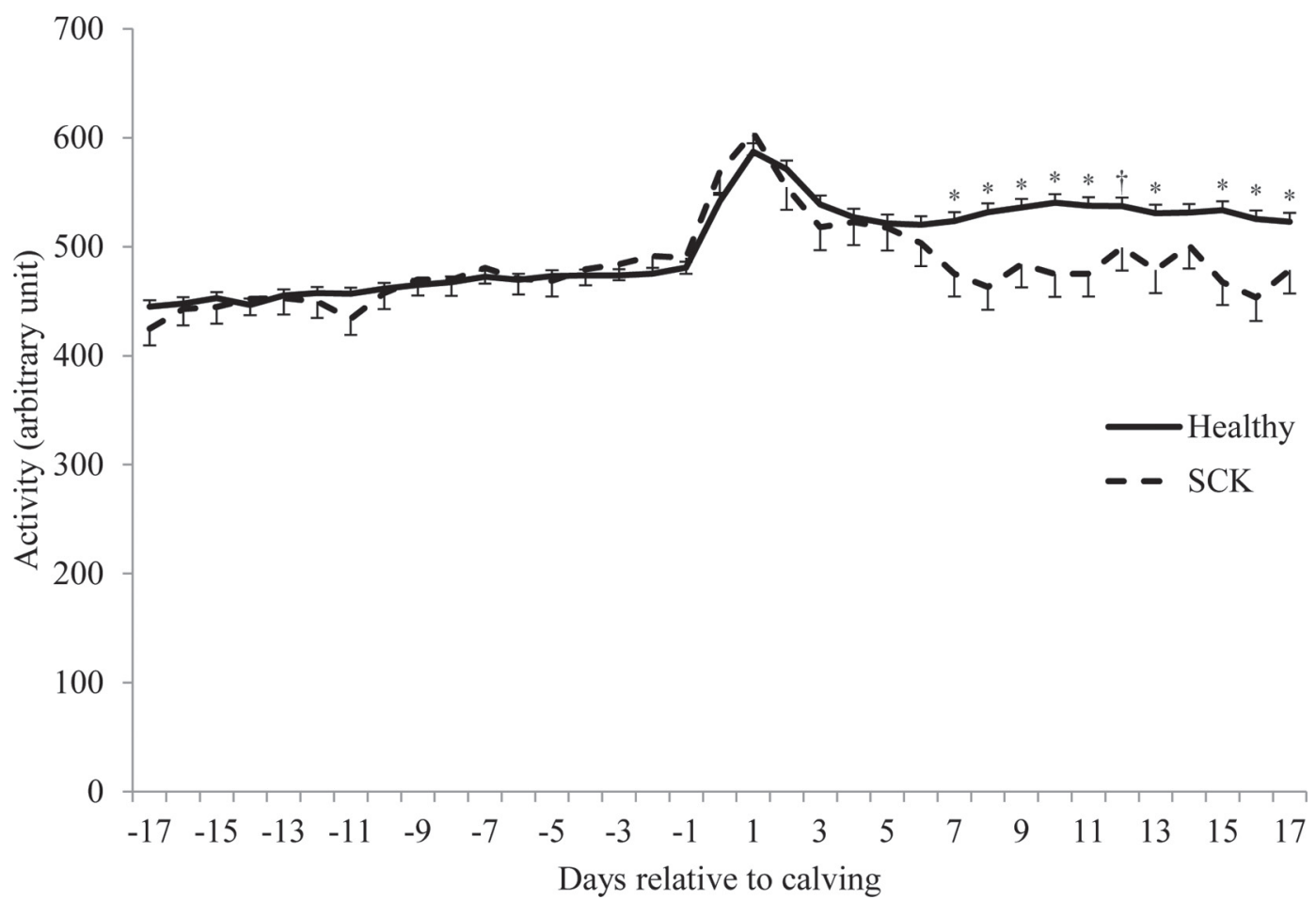

Figure 11. Association between occurrence of subclinical ketosis (SCK) and daily activity. Prepartum: occurrence of SCK, $P=0.96$; day relative to calving, $P<0.01$; interaction between occurrence of SCK and day relative to calving, $P=0.11$. Postpartum: occurrence of SCK, $P=$ 0.05 ; day relative to calving, $P<0.01$; interaction between occurrence of SCK and day relative to calving, $P<0.01$. ${ }^{*}$ Within day, means differ $(P<0.05)$; †within day, means tended to differ $(P<0.10)$.

Table 4. Daily activity according to animal characteristics and health events based on the multivariate analysis ${ }^{1}$

\begin{tabular}{|c|c|c|c|c|c|c|c|c|}
\hline \multirow[b]{2}{*}{ Item } & \multicolumn{2}{|c|}{$\begin{array}{c}\text { Activity } \\
\text { (arbitrary unit d } \pm \text { SEM) }\end{array}$} & \multicolumn{6}{|c|}{$P$-value } \\
\hline & Prepartum & Postpartum & Item & Item & Item $\times$ Day & Item & Day & Item $\times$ Day \\
\hline \multicolumn{3}{|l|}{ Number of calves } & 0.02 & $<0.01$ & $<0.01$ & 0.74 & $<0.01$ & 0.38 \\
\hline Singleton & $501.5 \pm 10.6$ & $544.1 \pm 19.8$ & & & & & & \\
\hline Twins & $457.9 \pm 18.6$ & $534.3 \pm 29.6$ & & & & & & \\
\hline Yes & $507.6 \pm 20.3$ & $561.8 \pm 29.3$ & & & & & & \\
\hline \multicolumn{3}{|l|}{ Subclinical hypocalcemia } & 0.34 & $<0.01$ & 0.24 & 0.47 & $<0.01$ & 0.80 \\
\hline No & $478.9 \pm 14.5$ & $533.3 \pm 22.1$ & & & & & & \\
\hline Yes & $488.3 \pm 14.3$ & $542.7 \pm 21.2$ & & & & & & \\
\hline \multicolumn{3}{|l|}{ Retained fetal membrane } & 0.31 & $<0.01$ & 0.93 & 0.08 & $<0.01$ & $<0.01$ \\
\hline No & $489.0 \pm 14.6$ & $543.3 \pm 14.1$ & & & & & & \\
\hline Yes & $474.3 \pm 16.3$ & $510.9 \pm 20.5$ & & & & & & \\
\hline Yes & $497.3 \pm 19.8$ & $519.4 \pm 22.5$ & & & & & & \\
\hline
\end{tabular}

${ }^{1}$ Variables that were retained in the final multivariate analysis models: Prepartum $=$ parity, days relative to calving, parity $\times$ days relative to calving, twinning, twinning $\times$ days relative to calving, stillbirth, locomotion score at $-17 \mathrm{~d}$ relative to calving. Postpartum $=$ parity, days relative to calving, parity $\times$ days relative to calving, calf sex, calf sex $\times$ days relative to calving, retained fetal membrane, retained fetal membrane $\times$ days relative to calving, subclinical ketosis, subclinical ketosis $\times$ days relative to calving, BCS at $3 \mathrm{~d}$ relative to calving. 
$24 \mathrm{~h}$ after calving even when cows are not moved to a maternity pen as they present signs of calving.

\section{CONCLUSIONS}

The most important factors associated with DRT during the prepartum period were days relative to calving, stillbirth, subclinical hypocalcemia, and RFM. During the postpartum period, the most important factors associated with DRT were days relative to calving, twinning, subclinical hypocalcemia, SCK, and RFM. Interestingly, during the prepartum period, only days relative to calving, twinning, and stillbirth were associated with activity, whereas days relative to calving, RFM, and SCK were associated with postpartum activity. The relatively minor differences in postpartum DRT and activity between healthy and unhealthy cows suggest that monitoring such outcomes may not be sufficient to identify all unhealthy cows in a herd. Visual observation of the DRT data from the current experiment suggests that, for the diagnosis of infectious and metabolic diseases, the change in DRT and activity of a cow over time may be more important than total DRT within a day.

\section{ACKNOWLEDGMENTS}

The authors are grateful to the owner and staff of Norswiss dairy (Rice Lake, WI) for their collaboration and support. The authors extend their appreciation to Select Sires Inc. (Plain City, OH) and SCR Engineers Inc. (Netanya, Israel) for partial financial support.

\section{REFERENCES}

Ballou, M. A., R. C. Gomes, S. O. Juchem, and E. J. DePeters. 2009. Effects of dietary supplemental fish oil during the peripartum period on blood metabolites and hepatic fatty acid compositions and total triacylglycerol concentrations of multiparous HO cows. J. Dairy Sci. 92:657-669.

Baumann, H., and J. Gauldie. 1994. The acute phase response. Immunol. Today 15:74-80.

Benzaquen, M. E., C. A. Risco, L. F. Archbald, P. Melendez, M. J. Thatcher, and W. W. Thatcher. 2007. Rectal temperature, calving-related factors, and the incidence of puerperal metritis in postpartum dairy cows. J. Dairy Sci. 90:2804-2814.

Dubuc, J., T. F. Duffield, K. E. Leslie, J. S. Walton, and S. J. LeBlanc. 2010. Risk factors for postpartum uterine diseases in dairy cows. J. Dairy Sci. 93:5764-5771.

Edwards, J. L., and P. R. Tozer. 2004. Using activity and milk yield as predictors of fresh cow disorders. J. Dairy Sci. 87:524-531.

Ferguson, J. D., D. T. Galligan, and N. Thomsen. 1994. Principal descriptors of body condition score in Holstein cows. J. Dairy Sci. $77: 2695-2703$.

Goff, J. P., N. J. Koszewski, J. S. Haynes, and R. L. Horst. 2012. Targeted delivery of vitamin $\mathrm{D}$ to the colon using $\beta$-glucuronides of vitamin D: Therapeutic effects in a murine model of inflammatory bowel disease. Am. J. Physiol. Gastrointest. Liver Physiol. 302:G460-469.

Goldhawk, C., N. Chapinal, D. M. Veira, D. M. Weary, and M. A. G. von Keyserlingk. 2009. Prepartum feeding behavior is an early indicator of subclinical ketosis. J. Dairy Sci. 92:4971-4977.

González, L. A., B. J. Tolkamp, M. P. Coffey, A. Ferret, and I. Kyriazakis. 2008. Changes in feeding behavior as possible indicators for the automatic monitoring of health disorders in dairy cows. J. Dairy Sci. 91:1017-1028.

Grummer, R. R., D. G. Mashek, and A. Hayirli. 2004. Dry matter intake and energy balance in the transition period. Vet. Clin. North Am. Food Anim. Pract. 20:447-470.

Hammon, D. S., I. M. Evjen, T. R. Dhiman, J. P. Goff, and J. L. Walters. 2006. Neutrophil function and energy status in Holstein cows with uterine health disorders. Vet. Immunol. Immunopathol. 113:21-29.

Hulbert, L. E., J. A. Carroll, N. C. Burdick, R. D. Randel, M. S. Brown, and M. A. Ballou. 2011. Innate immune responses of temperamental and calm cattle after transportation. Vet. Immunol. Immunopathol. 143:66-74

Huzzey, J. M., D. M. Veira, D. M. Weary, and M. A. von Keyserlingk. 2007. Prepartum behavior and dry matter intake identify dairy cows at risk for metritis. J. Dairy Sci. 90:3220-3233.

Jawor, P. E., J. M. Huzzey, S. J. LeBlanc, and M. A. G. von Keyserlingk. 2012. Associations of subclinical hypocalcemia at calving with milk yield, and feeding, drinking, and standing behaviors around parturition in Holstein cows. J. Dairy Sci. 95:1240-1248.

LeBlanc, S. 2010. Monitoring metabolic health of dairy cattle in the transition period. J. Reprod. Dev. 56:S29-S35.

Martinez, N., L. D. P. Sinedino, R. S. Bisinotto, E. S. Ribeiro, G. C. Gomes, F. S. Lima, L. F. Greco, C. A. Risco, K. N. Galvão, D. Taylor-Rodriguez, J. P. Driver, W. W. Thatcher, and J. E. P. Santos. 2014. Effect of induced subclinical hypocalcemia on physiological responses and neutrophil function in dairy cows. J. Dairy Sci. 97:874-887.

Mertens, D. R. 1997. Creating a system for meeting the fiber requirements of dairy cows. J. Dairy Sci. 80:1463-1481.

Murray, R. D., J. E. Horsfield, W. D. McCormick, H. J. Williams, and D. Ward. 2008. Historical and current perspectives on the treatment, control and pathogenesis of milk fever in dairy cattle. Vet. Rec. 163:561-565.

Oetzel, G. R. 1996. Effect of calcium chloride gel treatment in dairy cows on incidence of periparturient diseases. J. Am. Vet. Med. Assoc. 209:958-961.

Proudfoot, K. L., J. M. Huzzey, and M. A. von Keyserlingk. 2009. The effect of dystocia on the dry matter intake and behavior of Holstein cows. J. Dairy Sci. 92:4937-4944.

Schirmann, K., N. Chapinal, D. M. Weary, W. Heuwieser, and M. A. G. von Keyserlingk. 2012. Rumination and its relationship to feeding and lying behavior in Holstein dairy cows. J. Dairy Sci. 95:3212-3217.

Schirmann, K., N. Chapinal, D. M. Weary, L. Vickers, and M. A. G. von Keyserlingk. 2013. Short communication: Rumination and feeding behavior before and after calving in dairy cows. J. Dairy Sci. 96:7088-7092.

Schirmann, K., M. A. G. von Keyserlingk, D. M. Weary, D. M. Veira, and W. Heuwieser. 2009. Technical note: Validation of a system for monitoring rumination in dairy cows. J. Dairy Sci. 92:6052-6055.

Silva-del-Río, N., P. M. Fricke, and R. R. Grummer. 2010. Effects of twin pregnancy and dry period feeding strategy on milk production, energy balance, and metabolic profiles in dairy cows. J. Anim. Sci. 88:1048-1060.

Sprecher, D. J., D. E. Hostetler, and J. B. Kaneene. 1997. A lameness scoring system that uses posture and gait to predict dairy cattle reproductive performance. Theriogenology 47:1179-1187. 